\title{
IMPACT OF COMPUTERS IN THE CLASSROOM ENVIRONMENT - A DISTRACTION OR AN ESSENTIAL TOOL?
}

\author{
Gary Janchenko, Robert Morris University, janchenko@rmu.edu \\ Anthony Rodi, D.Sc. University of Pittsburgh, afrodi@katz.pitt.edu \\ Michael J. Donohoe, D.Sc. National Defense University, m.j.donohoe.civ@ndu.edu
}

\begin{abstract}
The use of laptops by students in the classroom has been a common practice for some time in both K-12 and Higher Education environments. With the infusion of technology comes new challenges in keeping the attention of students because of the lure of distraction brought about by laptops and smart phones. The study resulted in the following findings: (1) Laptops and Mobile devices are distracting; (2) Students are bored if not actively engaged in class; (3) Lecture courses create a disconnect with students; (4) Laptops hinder effective note-taking; (5) Laptops can distract other students in class; (6) The need to move from pure lecture classes to active learning. This exploratory study leads to the need for future research to determine success in non-lab courses where students are more engaged through active learning and innovative teaching and learning.
\end{abstract}

Keywords: Learning, Classroom Laptops, Teaching, Information Systems, Mobile Devices, Digital Natives, Active Learning

\section{INTRODUCTION}

The use of laptops by students in the classroom has been a common practice for some time in both K-12 and Higher Education environments. With the infusion of technology comes new challenges in keeping the attention of students because of the lure of distraction brought about by laptops and smart phones. The challenge presented to professors today is incorporating the technology with lectures, keep the students on-task, and engaged in the discussion. This challenge, however, is nothing new. Daydreaming, doodling, or using class time to work on other classwork has been common for ages (Martin, 2011).

Arguments can be made from faculty on whether or not the introduction of technologies such as tablet, laptops and desktops add any real value to the educational setting or if the computers simply are another distraction to overcome when teaching. While some openly embrace the use of technology, others point to the universities promotion of technology, lack of available resources, and lack of time to create technology-enhanced lectures or simply not wanting to use technology as a reason for its absence in many classroom. Furthermore, Zyad also cites a lack of incentives, symbolic or material incentives, as a major barrier, preventing faculty from incorporating technology into the classroom (Zyad, 2017).

The goal of this study is to review the existing research to examine to what extent technology, in the form of tablets, laptops and desktop computers are used in the classroom setting as well as information regarding faculty tendency to incorporate technology into lectures in an effort to stimulate discussion and recommend areas for future research. In addition, this paper looks at the impact of technology on student educational outcomes as a result of direct or indirect exposure to computers in the classroom.

\section{LITERATURE REVIEW}

The current generation of students consisting mostly of the millennial generation, has grown up with technology, so incorporating technology into learning provides a comfort zone for these students (Rodi, et al, 2013). Higher education has been struggling to accommodate the needs of Digital Natives with up-to-date technologies, flexible environments, and technology accommodations in the classroom and innovative teaching methods. The practice of 
bringing laptops or mobile devices into the classroom has become a double-edged sword involving the success and hindrance of learning.

\section{The Use of Laptops in the Classroom}

In Fried's article (2006), she discusses research conducted around the distractive nature of laptops in the classroom. Her research found that students surveyed revealed that many used their laptops for other reasons not class related. In fact, she mentions that students who are not performing well in a course have a tendency to bring a laptop to class to look busy or involved. In contrast, Fried goes on to state that effects of laptop usage varies based on the type of class and the faculty's ability to control its use. For example, large lecture classes with less faculty control may encourage laptop usage due to a student's disconnection with the instructor. Other classes, such as a lab-based class may incorporate laptop usage as favorable to learning (Fried, 2006). In a more recent study about laptop use in the college classroom, Patterson and Patterson (2017) determined that computer use in the classroom hinders learning and results in poorer academic outcomes. However, like other studies reveal, classrooms that integrate laptops into classroom activities and discussion may be more productive (Patterson \& Patterson, 2017). Neumann (2016) continues with a study on the challenges experienced by instructors with digital learners in the classroom. They tend to have a short attention span and their technologies such as laptops and phones become a distraction. They have high expectations of technology and have difficulty understanding any limitations of these technologies (Neumann, 2016).

Despite the correlations studied between laptop use in the classroom and student performance, students tend to refute the claims in favor of the continued use of their personal devices. Ravizza (2017), shares that $65 \%$ of students see no problems associated with using devices such as laptops or mobile phone to text others as long as they do not disturb other students (Ravizza et al, 2017). However, the perception the students who are texting have regarding disruption of their neighbors is subjective and not necessarily factual.

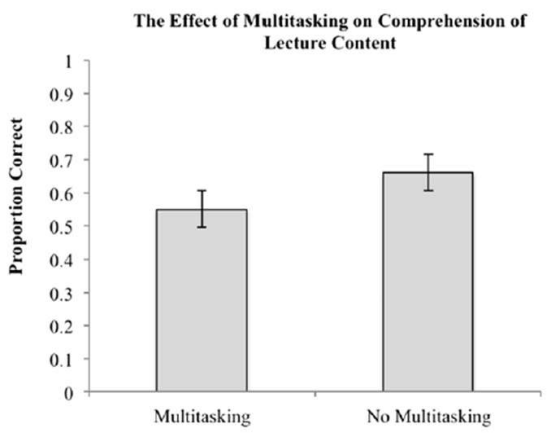

Figure 1. Performance on tests when students were interfacing with laptops was $11 \%$ lower than whose students who did not (Sana, 2013).

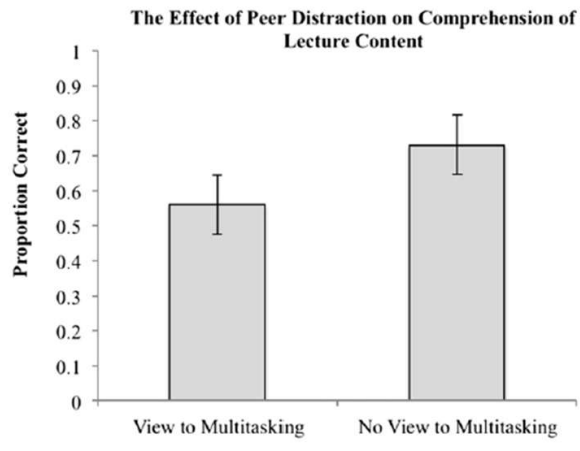

Figure 2. Students who were in direct view of peers who were engaged in multitasking performed $17 \%$ poorer than those who were not in direct view of another multitasking student (Sana, 2013).

Aa evidenced in their 2013 study, supporting other studies findings, students who were engaged in multitasking activities such as interacting with laptops or mobile devices tended to perform more poorly on tests than those students who focused on the lectures. The perception that some students have, that their own activities do not impact the performance of other students, is unfortunately wrong and the performance degradation is more pronounced at $17 \%$ worse than those students whom are not subjected to the multitasking of their neighbors (Sana, 2013).

Carter, et al. (2017) adds to this point by stating that even though students like to use their own devices, research finds little proof of positive effects and plenty examples of harmful effects of laptop usage in a classroom.

\section{Laptop use versus Longhand Note-taking on Test Performance}

Laptop and desktop computer use among students has become all but ubiquitous since the early 2000s with colleges often recommending students to bring their laptops into the learning environment. Under the guise of using the laptops for note-taking, students often stare up at professors, faces lit by glowing screens, often only catching pieces 
of the lecture. When test time comes, and the laptops are not allowed, are the laptops effective note-taking machines or are they just getting in the way and providing yet another distraction?

In Mueller's article (2014), she and coauthor Daniel Oppenheimer discuss two types of note taking processes: the encoding hypothesis and the external-storage hypothesis. During the processing that occurs while handwriting notes on paper in class, Mueller suggests, the process of encoding the information improves the student's learning and material retention. The external-storage hypothesis, by contrast, leaves the encoding and storage outside of brains and into the hard drives of the laptops to be accessed at a later date (Mueller \& Oppenheimer, 2014). Why the difference? Is it because the students are browsing the Internet instead of paying attention? Not necessarily. In their 2014 article, Muller and Oppenheimer discuss the processes of taking notes by interpreting and summarizing data, a method typically employed in longhand note taking, and the process of transcribing information verbatim from lecture material onto the laptop. The process of synthesizing data during long hand note taking, they argue, is what enables students to better understand and retain the information presented. In verbatim transcription, words are simply typed and little cognition is applied to the process.

Mueller and Oppenheimer concluded that students who took more notes, regardless of note-taking method, scored better on tests I their study. However, notetakers who tended to take longhand notes performed better than those students who transcribed material verbatim depending on the type of test. On tests that relied on fact recollection questions, the students who took verbatim notes performed slightly better than those who took notes via more traditional, longhand methods. Tests that relied on cognition and application of theories or the application of concepts, saw starkly different test outcomes favoring those students who relied on longhand note-taking methods (Mueller \& Oppenheimer, 2014).

The assertions by Mueller are confirmed by Stacy and Cain (2015) in their article, Note-Taking and Handouts in The Digital Age. Citing speed, searchability and legibility as three reasons to rely on laptops for note taking, Stacy also mentions the lures of multi-tasking as detractors that are common when using digital equipment (Stacy \& Cain 2015). Consistent with the findings of Mueller, Stacy and Cain claim that students who use laptops did well compared to the

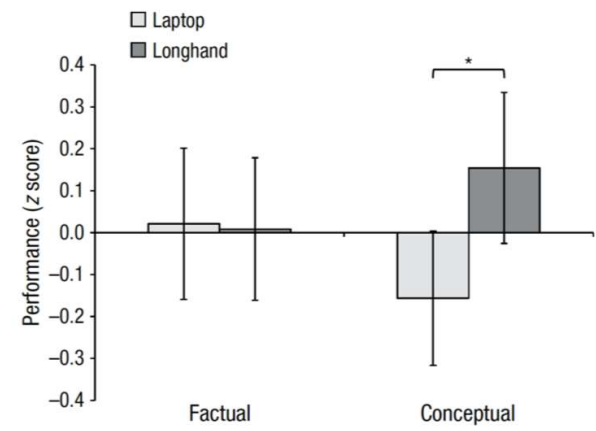

Figure 3. Student performance on factual recollection tests and the application of concepts as a result of note-taking methods. longhand note-takers in factual resting but had lower scored compared to the longhand note-taking students when faced with tests on conceptual materials.

Carter, et al (2017) goes on to explain that a student's ability to take notes quickly on a laptop led them to engage in transcription instead of identifying the most important points of a lecture. Therefore, students are so focused on capturing everything from a lecture in addition to multitasking, that they really do not focus on the lecture and as a result, do not perform as well on exams (Carter, et al., 2017).

\section{The Possible Disconnect in the Classroom}

Of course, the student is ultimately responsible for his or her own performance in the classroom but is the lure of distraction created by the laptop or mobile devices solely the student's dilemma? According to Ravizza (2016),

\begin{tabular}{|r|ccc|}
\hline Course Length (minutes) & 60 & 110 & 180 \\
\hline - Break (minutes) & - & 10 & 20 \\
Total Class Time (minutes) & 60 & 100 & 160 \\
- Distraction Time & 20 & 34 & 54 \\
Class Engagement Time & $\mathbf{4 0}$ & $\mathbf{6 6}$ & $\mathbf{1 0 6}$ \\
\hline
\end{tabular}

Figure 4. Examples of student distraction times and remaining active engagement time as a result of the findings of Ravizza et al (2016). students reported that they engaged in texting, looking at Facebook and browsing the Internet because they were bored (Ravizza, 2016). In their 2016 study, Ravizza el al, studied internet usage during a series of class meetings that lasted 1 hour and 50 minutes as well as the amount of times students self-reported their text message usage. The results of their study indicated that the students spend, on average, 37 minutes of the 1 hour and 50-minute class time on non-academic related activities such as browsing the Internet, watching videos, using social media, sending emails and 
more (Ravizza, 2016). Total instruction time of the observed classes was 100 minutes because of a ten-minute break and as a percentage; the students spent $33.6 \%$ of the class time on distractions. If a lecture period were 50 minutes, it would mean that the students would spend approximately 17 minutes on their computers and for classes that are 3hours in length, a weekly evening course meeting for example, the students would be distracted for an entire hour of the 3-hour course! Taking into account the distractions to the students near the distracted students, it is likely that there is a ripple effect in the classroom and the effect of the distractions are likely magnified.

Baker (2012) indicates that while laptops in the classrooms can be useful learning tools, $15 \%$ of the students lost focus and begin to look for distractions or begin to multitask (Baker el al, 2012). One of the reasons for the distractions or boredom is a result of the passive learning environment created through the use of lectures which rely heavily on PowerPoint (Baker et al, 2012). In his article, Baker continues by saying that the challenge of dealing with the distraction lies within academia and the willingness of anyone to do anything about it. Students and faculty alike agree that there are benefits to students having laptops in the classroom and studies indicate that $75 \%$ of students confirm that the use of laptops enhanced their learning experience (Skolnik \& Puzo, 2008). Skolnik and Puzo (2008) indicate that students agree that the use of PowerPoint can enhance the lecture material but also indicated that they were more likely to be browsing the Internet, texting or engaging in other types of multitasking. The extent to which technology in the classroom is beneficial depends on the structure of the lectures.

To what can the disconnect between students and staying on task during lectures be attributed? While it is likely that there are countless reasons to which the issue can be attributed, for the sake of this paper, we wish to point out the disconnect with the status-quo approach to lecturing and the gap it creates with the needs of today's new generation of learners. Many faculty members today, the majority of whom are baby boomers, view lectures as useful parts of a course despite studies that show that lectures can only benefit marginally from technology (Baker et al., 2012).

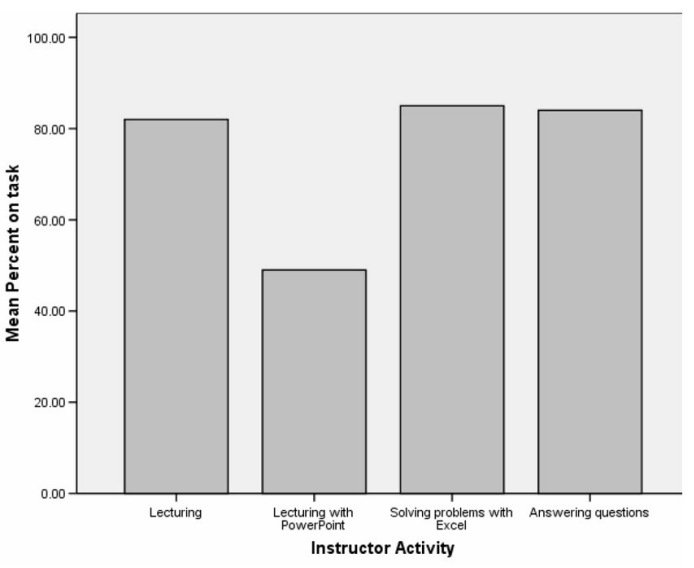

Figure 5: Students tend to be on-task with the faculty when lecturing, working in Excel or answering questions but are more likely to be off task when lectures consist mainly of PowerPoint. Millennials, who make up a majority of today's students, view the Power Points as a poorly disguised lecture-style method of instruction and as such are barriers to learning (Baker et al., 2012). Banning their laptops reinforces this viewpoint and can create animosity among the students. Remedying this situation is going to be largely up to the faculty and the challenge is to update course materials and make courses more interactive or limit the length of lectures and incorporating labs or other exercises. (Sana et al., 2013). Some researchers state that the use of laptops in the classroom is not the issue and instead point blame at faculty who refuse to engage the students more or set proper guidelines as to what behavior is acceptable and what is not (Young, 2006). Professors who have been able to turn their classrooms into active learning laboratories have reported little issues with students being distracted (Lang, 2017).

\section{FINDINGS}

This study concludes that laptops and mobile devices pose as a distraction in the classroom. There are a number of reasons for the distraction, including boredom, disengagement, and lack of active learning. The traditional lecture model, while still widely used, creates a disconnect with the students and leads them to other distractions. Interestingly, when students are using their laptops for taking notes, they are taking notes verbatim and not focused on active discussion or absorbing key points. They are merely taking down everything that is said and not sorting out important points. As a result, the students who use laptops for note taking do not perform a well on exams that require application of concepts, instead of memorization. Students using laptops in class who surf the web, watch sporting events, browse Facebook, or do other non-related work, miss up to one hour per week of valuable 
instruction time. In fact, they may be a distraction to students around them. Lastly, there is a need to move from pure lecture classes to active learning environments.

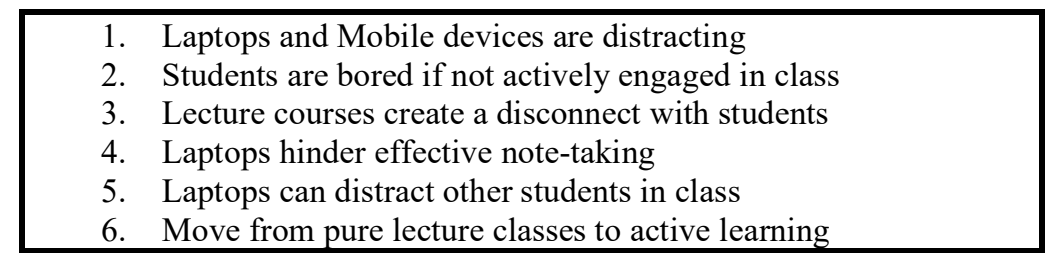

Figure 6. Summary of Impact of Computers in Classroom

\section{DISCUSSION, CONCLUSION AND FUTURE RESEARCH}

It is interesting but no surprise that the findings reflect laptops and devices in the classroom as a distraction. Many faculty would agree that most students do not use their laptops to stay actively engaged in the classroom topics or instruction. The Findings reveal other issues for the distraction. They shed light on teaching effectiveness. Sure, we can just ban all devices in the classroom and force students to listen to our boring lecture or view outdated PowerPoints. Does that solve the problem? We as educators need to look at innovative forms of engagement in the classroom. As our students get younger and younger, they are more embedded in technology. Students are bored in lecture classes and go to their comfort zones, meaning their laptops, or other mobile devices. The research reflects on effective teaching models that incorporates engagement into the classroom. Of course, lab based courses integrate engagement and technology in the learning and students actively participate due to the nature of the lab course. However, the challenge is to incorporate active learning into the lecture-based classroom. Some examples may be using case-based discussions or projects by using case studies. Other suggestions are to embrace the use of laptops by creating in class activities that support the lecture. This leads to the need for additional research. While we know that laptops are a distraction, future research would determine success in non-lab courses where students are more engaged through active learning and innovative teaching and learning.

\section{REFERENCES}

Baker, W. M., Lusk, E. J., Neuhauser, K. L. (2012). On the Use of Cell Phones and Other Electronic Devices in the Classroom: Evidence from a Survey of Faculty and Students. Journal of Education for Business, 87(5), 275-289.

Carter, S. P., Greenberg, K., \& Walker, M. (2017). Should Professors Ban Laptops? How Classroom Computer Use Affects Learning. Education Next. FALL, 17(4). http://educationnext.org/should-professors-banlaptops-classroom-computer-use-affects-student-learning-study/

Fried, C. B. (2006). In Class Laptop Use and its Effects on Student Learning. Computers and Education, 50(3), 906-914.

Lang, J. M., (2017). The Distracted Classroom: Transparency, Autonomy and Pedagogy. Chronicle of Higher Education, 63(42), 26.

Martin, L. R. (2011). Teaching Business Statistics in a Computer Lab: Benefit or Distraction? Journal of Education for Business, 86(6).

Mueller, P. A., \& Oppenheimer, D. M. (2014) The Pen Is Mightier Than the Keyboard. Advantages of Longhand Over Laptop Note Taking. Association for Psychological Science, 25(6), 1159-1168.

Neumann, C. (2016). Teaching digital natives: promoting information literacy and addressing instructional challenges. Reading Improvement, 53(3), 101+. Retrieved from 
http://link.galegroup.com.pitt.idm.oclc.org/apps/doc/A465436554/AONE?u=upitt_main\&sid=AONE\&xid= ff0e 7372

Patterson, R.W., \& Patterson, R.W. (2017). Computers and productivity: Evidence from laptop use in the college classroom. Economics of Education Review, 57, 66-79.

Ravizza, Susan M., Uitvlugt, Mitchell G., Fenn, \& Kimberly M. (2016). Logged In and Zoned Out: How Laptop Internet Use Relates to Classroom Leaning. Association for Psychological Science, 28(2). 171-180. http://journals.sagepub.com/doi/10.1177/0956797616677314

Rodi, A.F., DeLorenzo, G., \& Kohun, F. (2013). Does a Learning Management System Discourage Student Attendance and Interaction? Issues in Information Systems, 14(2), 438-443.

Sana, F., Weston, T., \& Cepeda, N. J. (2013). Laptop Multitasking Hinders Classroom Learning for Both Users and Nearby Peers. Computers \& Education, 62, 24-31.

http://linkinghub.elsevier.com/retrieve/pii/S0360131512002254

Skolnik, R., \& Puzo, M. (2008). Utilization of Laptop Computers in the School of Business Classroom. Academy of Educational Leadership Journal, 12(2), 11.

Stacy, E. M., \& Cain, J. (2015). Note-taking and Handouts in The Digital Age. American Journal of Pharmaceutical Education, 79(7), 107, Retrieved from: http://www.ajpe.org/doi/10.5688/ajpe797107

Young, J. R. (2006). The Fight for Classroom Attention: Professor vs. Laptop. Chronicle of Higher Education, 52(39), 27-29.

Zyad, H. (2016). Integrating Computers in the Classroom: Barriers and Teaches' Attitudes. International Journal of Instruction, 9(1), 65-78. 